\title{
PERANCANGAN ANIMASI INTERAKTIF BELAJAR BERHITUNG BERBASIS MULTIMEDIA PADA TK-IT AL WASHLIYAH KLAMBIR LIMA HAMPARAN PERAK
}

\author{
Barany Fachri ${ }^{1}$, Hendry ${ }^{2}$ \\ Fakultas Sains dan Teknologi Jurusan Sistem Komputer Universitas Pembangunan Panca budi \\ Jl.Jend Gatot subroto Km 4,5 Medan \\ lbarany fachriedosen.pancabudi.ac.id, 2hendryedosen.pancabudi.ac.id
}

\begin{abstract}
Education plays a role in the intellectual life of the nation. So that in this case the need for a technology to improve the quality of a school. This study discusses the design of interactive animation of learning to count for children at TK-IT AL Washliyah Klambir Lima Hamparan Perak. The main purpose of designing this learning media is to make new innovations in the teaching and learning process in schools especially students to be more interesting, fun, effective, and not waste a lot of energy for teachers to teach.
\end{abstract}

Keywords - Design, Animation, new innovation, interesting and fun, Adobe Flash, Multimedia.

Abstrak - Pendidikan sangat berperanan dalam mencerdaskan kehidupan bangsa. Sehingga dalam hal ini diperlukannya suatu teknologi untuk meningkatkan mutu suatu sekolah. Penelitian ini membahas mengenai perancangan animasi interaktif belajar berhitung untuk anak pada TK-IT AL Washliyah Klambir Lima Hamparan Perak. Tujuan utama perancangan media pembelajaran ini adalah untuk membuat inovasi baru dalam proses belajar mengajar di sekolah khususnya siswa/i agar lebih menarik, fun, efektif, serta tidak membuang banyak tenaga bagi para guru untuk mengajar.

Kata Kunci - Perancangan, Animasi, inovasi baru, menarik dan fun, Adobe Flash, Multimedia.

\section{PENDAHULUAN}

Pada saat ini informasi sudah menjadi kebutuhan dasar bagi setiap orang dan menjadi fasilitator utama bagi kegiatan-kegiatan yang memberikan andil besar terhadap perubahan yang mendasar pada pola pikir manusia. Perkembangan dalam bidang ilmu teknologi dan informasi yaitu komputer membuat manusia menginginkan apa yang kita lakukan ingin serba cepat, mudah dan efesien.

Dengan teknologi informasi yang berbasis multimedia diharapkan bisa memberikan peranan penting dalam proses penyaluran informasi. Informasi disebarluaskan melalui banyak cara salah satunya dengan aplikasi multimedia, khususnya dibidang pendidikan. Apabila membahas tentang mutu pendidikan maka tidak lepas dari kegiatan belajar mengajar di sekolah yang merupakan kegiatan paling penting dan mendasar. Animasi merupakan bentuk visual yang bergerak yang dapat dimanfatkan untuk menjelaskan materi pembelajaran yang sulit disampaikan secara konvensional. Bagi pihak pengajar, animasi daapat mempermudah proses pembelajaran dan pengajaran dalam penyampaian materi kepada anak.

Perancangan animasi tentang belajar berhitung untuk anak merupakan suatu animasi yang seharusnya sudah bisa diterapkan di era modern ini. Selama ini belajar berhitung hanya didapat melalui referensi buku. Para murid hanya diperlihatkan gambar dan tulisan satu per satu oleh guru melalui metode ceramah. Dengan adanya animasi berbasis multimedia ini tentunya akan membuat proses belajar mengajar menjadi lebih menarik dan diharapkan dapat menambah ilmu pengetahuan dan meningkatkan motivasi serta hasil belajar siswa. karena dalam animasi akan di lengkapi banyak informasi tentang pelajaran berhitung seperti penjumlahan, perkalian pengurangan pembagian dan lain sebagainya.

\section{LANDASAN TEORI}

\section{A. Animasi}

Menurut Teguh Wahyono (2006), animasi pada dasarnya adalah menggerakkan objek agar tampak lebih dinamis. Sebelum era komputerisasi seperti sekarang, animasi merupakan proses yang rumit dan menyita banyak waktu dan tenaga. Contoh animasi misalnya banner, kartu ucapan online, kartun, iklan, dan sejenisnya (Teguh dalam Linda dkk, 2013: 24).

\section{B. Interaktif}

Pengertian interaktif terkait dengan komunikasi dua arah atau lebih dari komponenkomponen komunikasi yaitu hubungan antara manusia (sebagai user/pengguna produk) dan komputer (software/aplikasi/produk dalam format file tertentu, dikemas dalam bentuk CD). Dengan demikian produk/CD/aplikasi yang diharapkan memiliki hubungan dua arah atau timbal balik antara software atau aplikasi dengan usernya.(Dwi Maryani, 2014). 


\section{Belajar dan Pembelajaran}

Pembelajaran adalah usaha sadar dari guru untuk membuat siswa belajar, yaitu terjadinya perubahan tingkah laku pada diri siswa yang belajar, dimana perubahan itu dengan didapatkannya kemampuan baru yang berlaku dalam waktu yang relative lama dan karena adanya usaha (Dwi Maryani, 2014).

\section{Berhitung}

Menurut Rachmawati (2008), berhitung merupakan usaha melakukan, mengerjakan hitungan seperti menjumlah, mengurangi serta memanipulasi bilangan bilangan dan lambang-lambang matematika.

\section{E. Multimedia}

Menurut M.Suyanto, (2003), multimedia adalah kombinasi dari komputer dan video (Rosch, 1996). Atau multimedia secara umum merupakan kombinasi tiga elemen yaitu: suara, gambar dan teks (Mc Cormick, 1996). Atau multimedia adalah kombinasi dari paling sedikit 2 media input atau output dari data, media ini dapat berupa audio (suara, music), animasi, video, teks, grafik dan gambar (Turban dkk, 2002). Atau multimedia merupakan alat yang menciptakan presentasi yang dinamis dan interaktif yang mengkombinasikan teks, grafik, animasi, audio dan gambar video (Robin dan Linda, 2001). Demikian juga jika pengguna tidak mempunyai ruang untuk berkreasi dan menyumbangkan ide sendiri, maka namanya televisi, bukan multimedia. Dari beberapa definisi di atas, maka multimedia ada yang online (internet) dan multimedia yang offline (tradisional) (Denny Riska Novitasari, 2010: 22).

\section{F. Adobe Flash}

"Adobe Flash adalah software multimedia unggulan dan populer untuk menambahkan animasi dan interaktif website" (Andi Sunyoto, 2005). Flash tidak hanya digunakan untuk aplikasi web, tetapi dapat dikembangkan untuk membangun aplikasi desktop karena aplikasi Flash selain dikompilasi menjadi format .swf, Flash juga dapat dikompilasi menjadi format exe. Flash menggunakan bahasa pemrograman bernama ActionScript. Flash lahir dari kepala seseorang bernama Jonathan Gay. Jon yang gemar menulis game dan membuat animasi di komputer. Ia menciptakan game Mac Airborne! tahun 1985, ketika ia masih duduk di bangku sekolah.

Menurut buku yang di tulis oleh Andi Sunyoto pada halaman 1 yang berjudul "Adobe Flash $+\mathrm{XML}=$ Rich Multimedia application", bahwasanya sebelum tahun 2005 Flash dirilis oleh Macromedia. Flash 1.0 diluncurkan pada tahun 1996 setelah Macromedia membeli program animasi vektor bernama FutureSplash.

\section{G. Adobe Flash Professional CS6}

Adobe Flash Professional CS6 adalah salah satu perangkat lunak komputer yang merupakan produk unggulan Adobe Systems. Adobe Flash Professional CS6 merupakan software yang digunakan untuk menciptakan animasi dan konten multimedia (Madcoms, 2013). Desain pengalaman immersive interaktif yang hadir secara konsisten diseluruh desktop dan beberapa perangkat, termasuk tablet, smartphone, dan televisi (Madcoms, 2013). Dengan Flash Professional CS6 kita dapat dengan mudah menggabungkan beberapa simbol dan urutan animasi menjadi lembaran sprite tunggal dan di optimalkan untuk alur kerja yang lebih baik, dibuat lebih menarik dengan konten menggunakan ekstensi asli untuk mengakses kemampuan perangkat secara spesifik, dan menciptakan aset dan animasi untuk di gunakan dalam HTML 5. Adobe Professional CS6 telah membuktikan dirinya sebagai program animasi dua dimensi berbasis vector dengan kemampuan professional. Dalam perkembangannya, Adobe Flash selalu melakukan banyak penyempurnaan pada setiap versinya. Adobe Flash Professional CS6 menghadirkan fitur-fitur baru yang menjadikan flash semakin diakui sebagai program yang handal (Madcoms , 2013).

\section{Menjalankan Adobe Flash Profesional CS6}

Cukup dengan meng-klik tombol Start $>A l l$ Program > Adobe Master Collection Pro CS6, atau dengan dobel klik ikon Adobe Flash Pro CS6 yang ada di desktop, maka akan ditampilkan gambar seperti berikut:

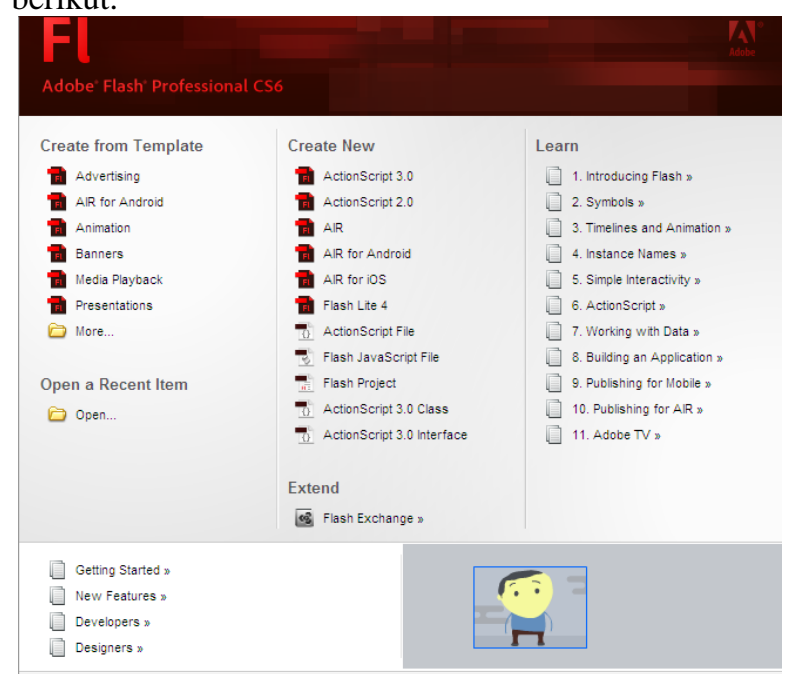

Gambar 1. Tampilam Program Adobe Flash Pro CS6

Berikut adalah penjelasan dari beberapa bagian dalam jendela tampilan awal Adobe Flash:

a. Open a Recent Item, untuk membuka file yang pernah dibuka atau baru saja tersimpan.

b. Open, untuk membuka file yang pernah disimpan.

c. Creat New, digunakan untuk membuat dokumen baru. Anda tinggal memilih salah 
satu dari beberapa pilihan lembar kerja yang akan digunakan.

d. Creat From Template, digunakan untuk membuka format lembar kerja yang telah disedikan secara defult.

e. Learn, untuk mempelajari apa saja yang ada di dalam Adobe Flash CS6. Fasilitas ini terhubung langsung ke web page adobe.com

f. Don't show again, untuk menyembunyikan tampilan awal jendela program Adobe Flash.

\section{H. Adobe Photoshop}

Menurut Madcoms 2013, Adobe Photoshop adalah perangkat lunak editor citra buatan Adobe Systems yang dikhususkan untuk pengeditan foto/gambar dan pembuatan efek. Perangkat lunak ini banyak digunakan oleh fotografer digital dan perusahaan iklan sehingga dianggap sebagai pemimpin pasar (market leader) untuk perangkat lunak pengolah gambar/foto, dan, bersama Adobe Acrobat, dianggap sebagai produk terbaik yang pernah diproduksi oleh Adobe Systems. Versi kedelapan aplikasi ini disebut dengan nama Photoshop CS (Creative Suite), versi Sembilan disebut Adobe Photoshop CS2, versi sepuluh sisebut Adobe Photoshop CS3, versi kesebelas adalah Adobe Photoshop CS4, versi kedua belas adalah Adobe Photoshop CS5, dan versi yang terakhir (ketigabelas) adalah Adobe Photoshop CS6. Photoshop tersedia untuk Microsoft Windows, Mac OS X, dan Mac OS versi 9 ke atas juga dapat digunakan oleh sistem operasi lain seperti Linux dengan bantuan perangkat lunak tertentu seperti CrossOver.

\section{METODE PENELITIAN}

\section{A. Kerangka Kerja Penelitian}

Kerangka kerja ini merupakan langkahlangkah yang akan dilakukan dalam rangka penyelesaian masalah yang akan dibahas. Gambar 3.1 di bawah ini merupakan kerangka kerja (frame work) yang digunakan dalam penelitian ini:

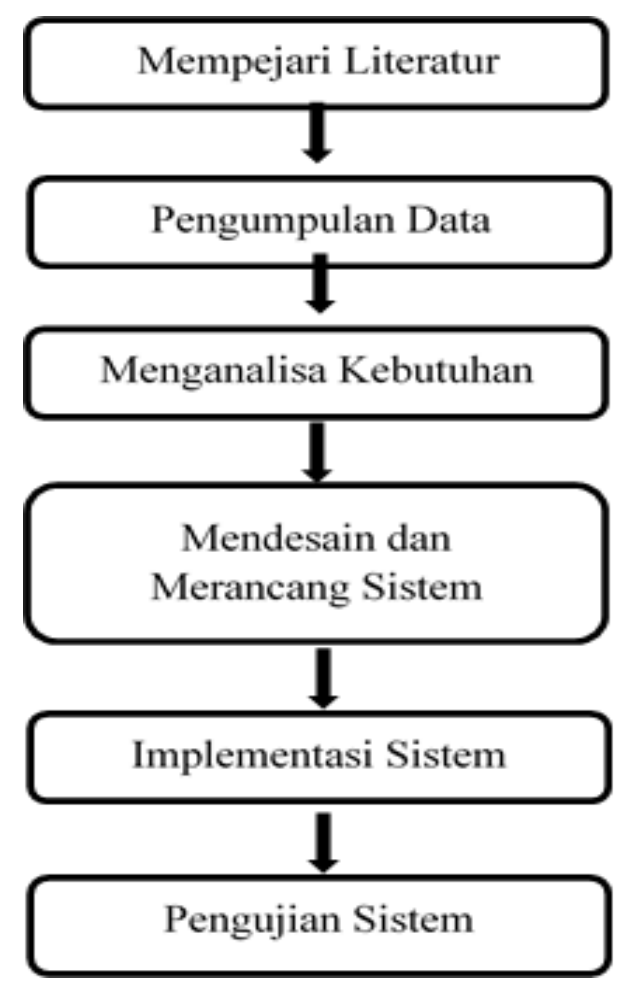

Gambar 2. Kerangka Kerja Penelitian

Berdasarkan gambar 2 penulis dapat menjelaskan beberapa kerangka kerja yang akan dilakukan dalam penelitian ini, yaitu sebagai berikut :

\section{Mempelajari Literatur}

Pada penelitian ini dipelajari literatur yang berhubungan dengan permasalahan. Kemudian literatur yang dipelajari diseleksi untuk dapat ditentukan literatur mana yang akan digunakan dalam penelitian. Sumber literatur didapatkan dari perpustakaan, jurnal, artikel dan konsep-konsep lain yang mendukung dalam menyelesaikan sistem yang akan dibangun termasuk referensi.

2. Pengumpulan Data

Dalam melakukan penelitian ini, pengumpulan data dan informasi pada tahap ini dilakukan untuk mengetahui mengenai sistem yang diteliti. Dari data dan informasi yang dikumpulkan akan didapat data untuk pendukung penelitian serta pengumpulan data dilakukan untuk mengetahui kebutuhan dari pengguna. Metode yang digunakan penulis untuk pengumpulan data adalah sebagai berikut :

a. Observasi

Observasi berguna untuk melakukan pengumpulan data dan observasi dengan langsung terjun kelapangan pada pihak-pihak yang terkait dalam menyelesaikan penelitian ini dimana informasi dan materi akan diperoleh sebagai bahan dari rancang bangun sistem. 
b. Wawancara

Melakukan wawancara pada pihak yang berkaitan dengan alur permasalahan. Wawancara ini dilakukan untuk mendapatkan bahan penulisan dan penjelasan pengamatan yang dilakukan.

3. Analisa Kebutuhan

Analisis dapat didefinisikan sebagai penguraian dari suatu sistem informasi yang utuh kedalam bagian-bagian komponennya. Analisa kebutuhan ini bertujuan untuk mengetahui apa saja yang dibutuhkan dalam perancangan sistem yang di bangun dan mengetahui kebutuhan-kebutuhan pendukung dari perancangan sistem.

4. Desain dan Perancangan Sistem

Kegiatan desain sistem dilakukan untuk sebagai awal dari perancangan sistem yang akan dibangun sesuai kebutuhan. Pada tahap ini akan dilakukan pemodelan terhadap sistem yang akan dibangun dengan pemodelan UML (Unified Modelling Language). Dan pada tahap ini dilakukan perancangan antar muka terhadap sistem yang akan dibuat.

\section{Implementasi Sistem}

Implementasi sistem dilakukan sesuai desain dan rancangan antar muka aplikasi yang akan dibangun. Pada tahap ini melakukan pengkodingan atau pembuatan program sehingga sistem yang dirancang dapat digunakan oleh pengguna.

\section{ANALISA DAN PEMBAHASAN}

\section{A. Analisa Masalah}

Dalam proses penelitian ini ada beberapa permasalahan yang dapat dirumuskan antara lain Bagaimana cara membuat animasi interaktif belajar berhitung untuk anak dengan menggunakan Adobe Flash CS6, apakah animasi interaktif dengan menggunakan Adobe Flash CS6 lebih efektif bila dibandingkan dengan metode ceramah.

B. Perancangan Sistem

1. Diagram Konteks (Context Diagram)

Diagram Konteks merupakan langkah awal yang dilakukan sebelum membuat data flow diagram. Suatu diagram context hanya mengandung satu proses saja. Dimana proses ini mewakili seluruh proses sistem yang menggambarkan hubungan input/output antara sistem dengan kesatuan luar. Berikut ini adalah context diagram:

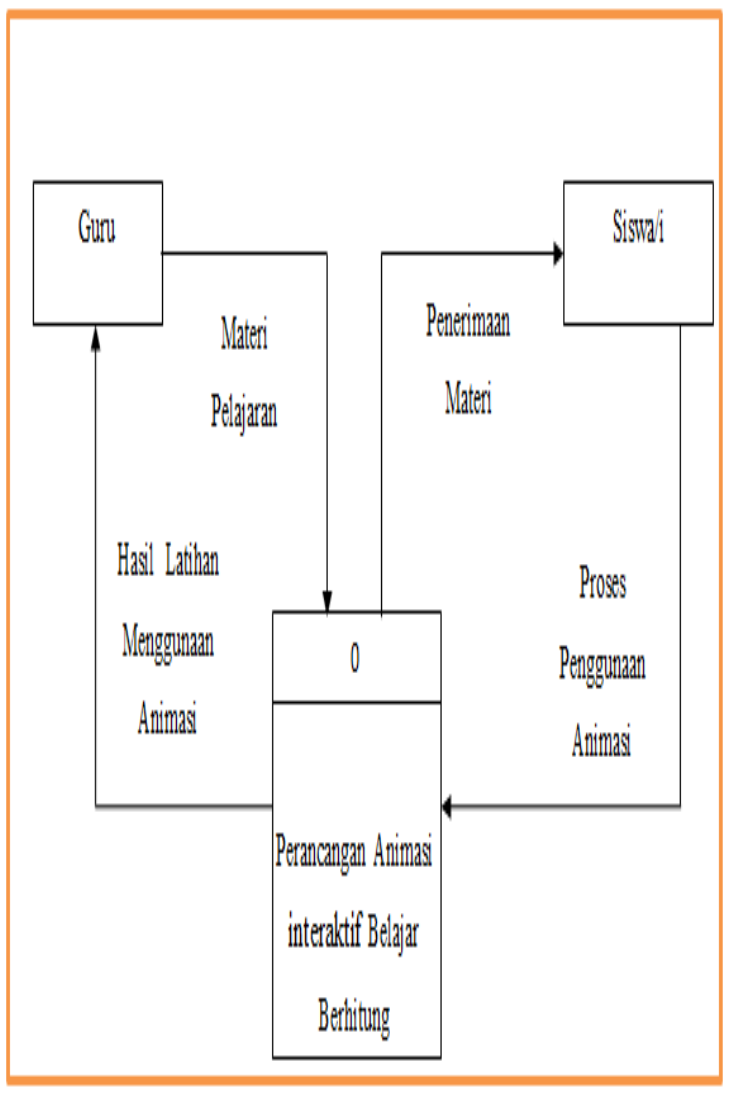

Gambar 3. Konteks Diagram

2. Diagram Alir Data (Data Flow Diagram)

Data Flow Diagram (DFD) adalah alat dokumentasi grafik yang menggunakan nomor kecil dari simbol untuk menggambarkan aliran data. Keuntungan menggunakan Data Flow Diagram (DFD) adalah memudahkan pemakai yang kurang menguasai bidang komputer untuk mengerti sistem yang akan dikembangkan 


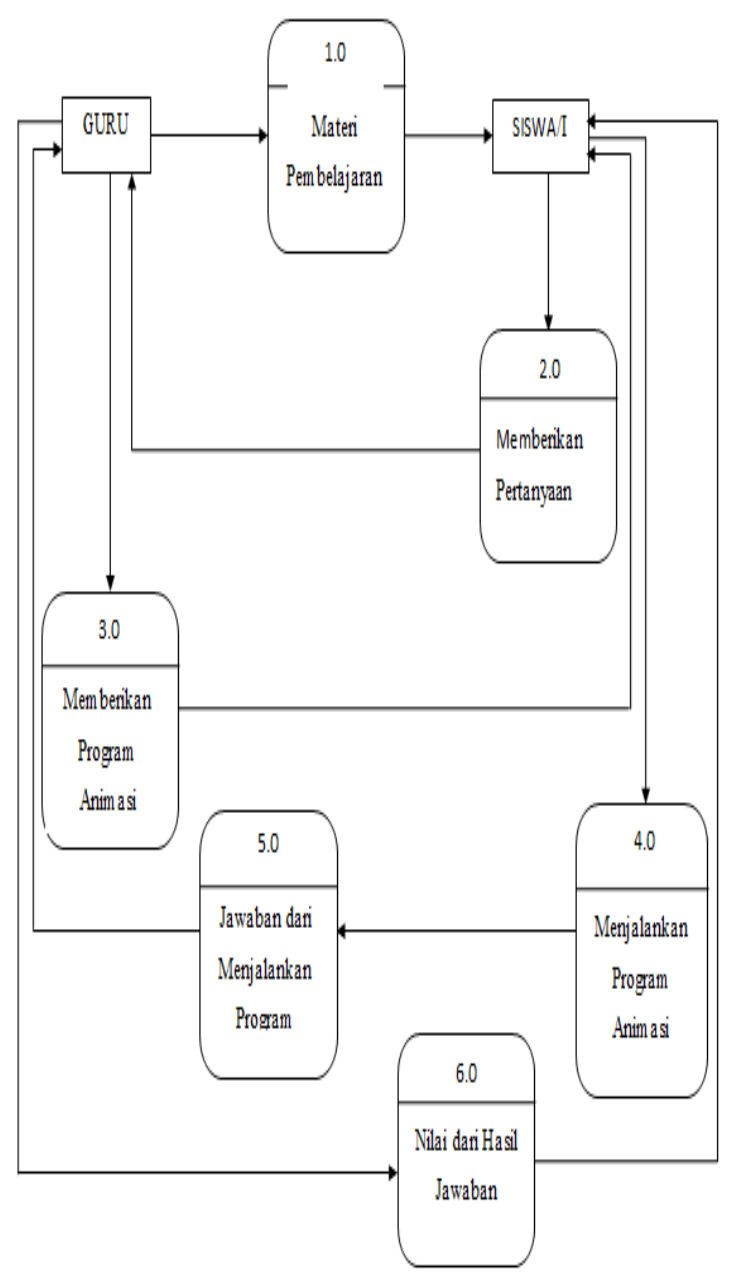

Gambar 4. Data Flow Diagram

C. Implementasi

1. Perancangan Animasi

Dalam merancang animasi interaktif ini dibagi menjadi dua proses, yaitu proses pengumpulan bahan/materi dan proses editing dengan menggunakan beberapa software.

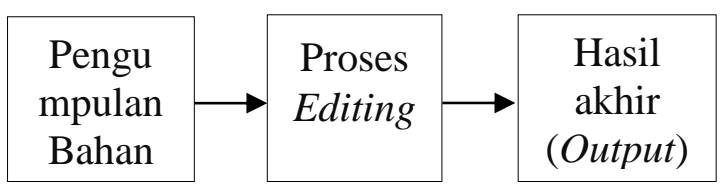

Gambar 5. Proses Perancangan Animasi

a. Pengumpulan Materi

Materi yang dimaksud adalah tentang belajar berhitung pada anak usia dini, rekaman suara sebagai penjelasan dalam bahasa indonesia yang diperlukan untuk perancangan animasi interaktif belajar berhitung.

\section{b. Proses Editing}

Didalam proses perancangan animasi interaktif belajar berhitung, editing yang dilakukan tidak hanya memerlukan satu perangkat lunak, tetapi dilakukan dengan beberapa perangkat lunak. Untuk lebih jelasnya, proses pembuatan/editing media pembelajaran tersebut dapat dilihat pada gambar dibwah ini.

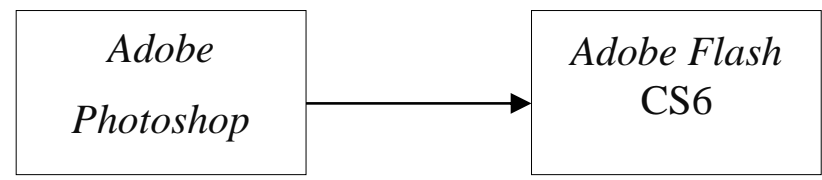

Gambar 6. Proses Editing

D. Implementasi Hasil Rancangan Program

Didalam melakukan pengimplementasian media pembelajaran berbasis multimedia flash ini, perlu dilakukan uji coba kembali apakah setiap bagainbagian atau komponen-komponen program tersebut dapat berjalan dengan baik sesuai yang dirancang atau tidak. Carannya dengan menekan pada keyboard "ctrl + enter".

Berikut ini adalah tampilan disaat kita menjalankan aplikasi tersebut:

1. Tampilan Halaman Intro

\begin{tabular}{|c|}
\hline AYO BELAJAR BERHITUNG \\
PENAMBAHAN \\
PENGURANGAN \\
PERKALIAN \\
PEMBAGIAN \\
BACKGROUND \\
\\
NEXT \\
\hline
\end{tabular}

Gambar 7. Rancangan Halaman Tampilan Awal

Keterangan Gambar :

1. Next

Pada tombol next akan menampilkan menu utama 
2. Tampilan Halaman Menu Utama

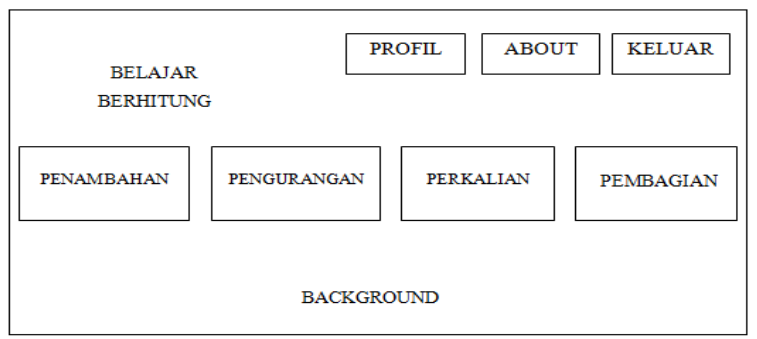

Gambar 8. Rancangan Halaman Menu Utama

3. Tampilan Halaman Penambahan

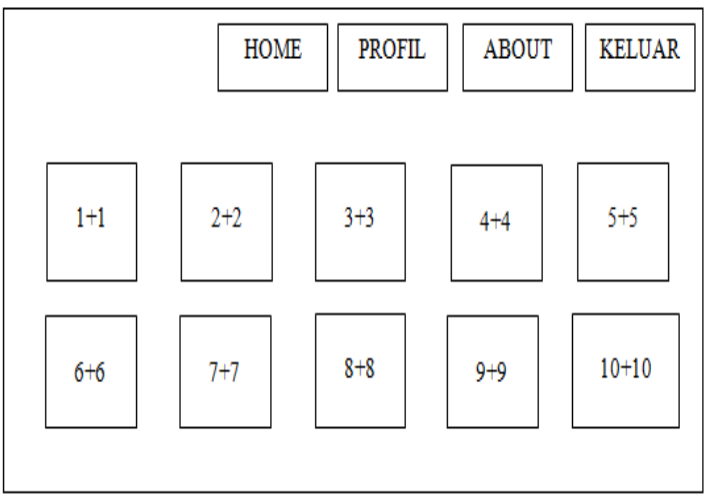

Gambar 9. Halaman Penambahan

4. Tampilan Halaman Pengurangan

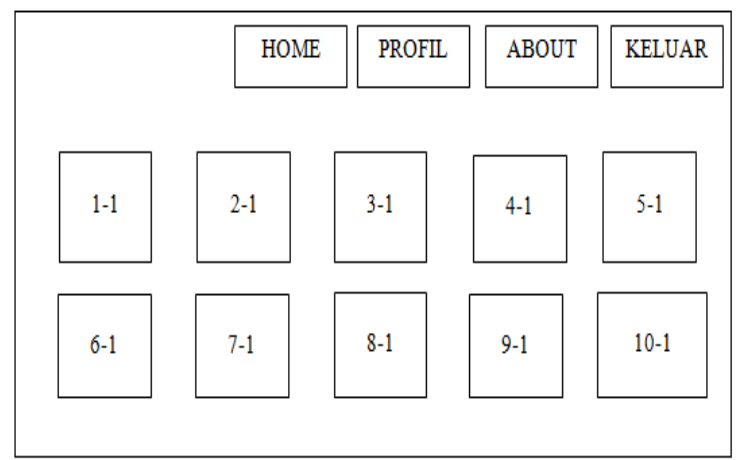

Gambar 10. Halaman Pengurangan
5. Tampilan Halaman Perkalian

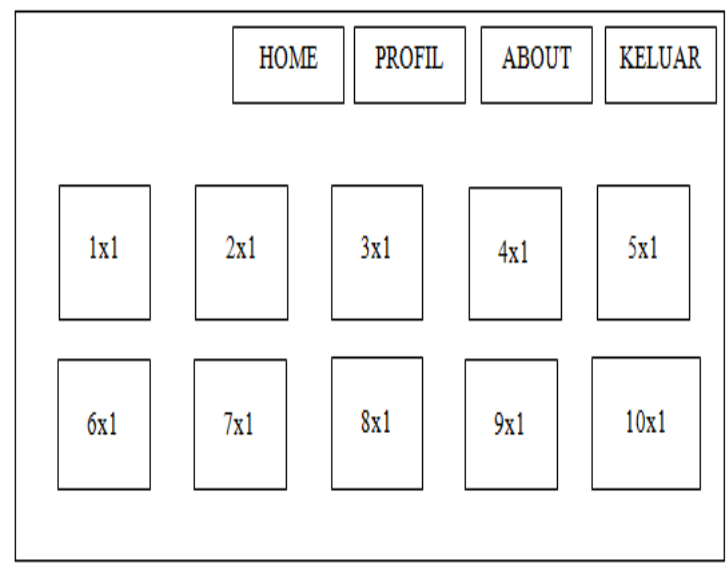

Gambar 11. Halaman Perkalian

6. Tampilan Halaman Pembagian

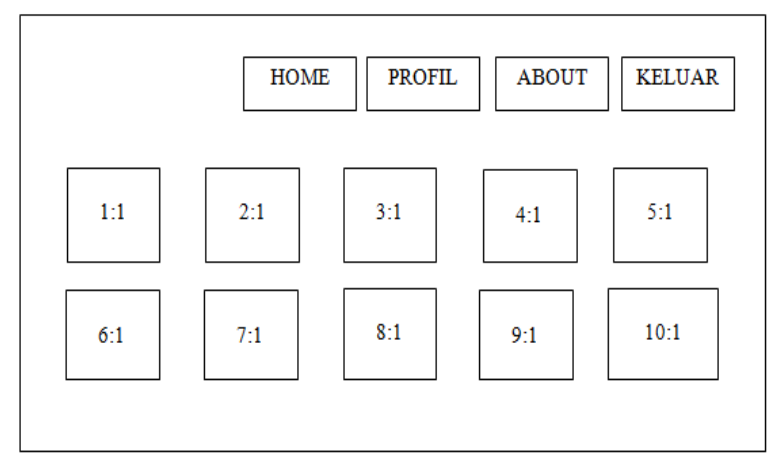

Gambar 12. Halaman Pembagian

\section{PENUTUP}

A. Kesimpulan

Dari hasil penelitian perancangan animasi interaktif pembelajaran berbasis multimedia menggunakan Adobe Flash CS6 pada pembelajar berhitung untuk anak pada TK-IT AL Washliyah Klambir Lima Hamparan Perak, maka penulis dapat menyimpulan sebagai berikut:

1. Dengan dibuatnya animasi interaktif ini akan memberikan kemudahan bagi pengajar sebagai alternatif baru dalam menyajikan sebuah media pembelajaran yang membantu dalam proses belajar mengajar.

2. Dengan adanya animasi pembelajaran berbasis multimedia ini maka proses belajar mengajar jadi lebih menarik dan menyenangkan. 


\subsection{Saran}

Adapun saran yang dapat diberikan berkaitan dengan Penulisan Tugas Akhir ini yaitu:

1. Sebaiknya Animasi yang dirancang oleh Penulis, dapat diimplementasikan pada bidang pendidikan.

2. Untuk pengembangan selanjutnya agar Animasi menggunakan Adobe Flash CS6 ini lebih menarik lagi, penulis menyarankan agar Animasi ini mampu menyertakan didalamnya komponen video.

3. Diharapkan Animasi Interktif ini dapat digunakan pada sistem android atau berbasis aplikasi video interaktif.

Demikian kesimpulan dan saran yang penulis sampaikan. Penulis sadar bahwa dalam perancangan media pembelajaran berbasis multimedia menggunakan Adobe Flash CS6 ini masih banyak kekurangan, kesalahan, serta kelemahan. Oleh karena itu penulis masih membutuhkan saran dan kritik yang bersifat membangun dari para pembaca.

\section{DAFTAR PUSTAKA}

[1] Anugerah Putri Weni Tria dan Hariani Sri. Penggunaan Media Film Kartun Untuk Meningkatkan Keterampilan Menyimak Cerita di Sekolah Dasar. Surabaya. Jurnal Penggunaan Media Film Kartun Untuk Meningkatkan Keterampilan Menyimak.
[2] Ariyanti Sri dan Mesriati Titik. 2016.Perancangan Aimasi Interaktif Pembelajaran Asmaul Husna. Bekasi. Jurnal Teknik Komputer AMIK BSI volume I1. ISSN 2442-2436. Hal.116-121.

[3] Madcoms, 2013.Pasti Bisa Belajar Sendiri AdobeFlash ProCS6. Andi : Yogyakarta. Slametriyanto. 2014.Sejarah Flash.

[4] Maryani Dwi. 2014. Pembuatan Media Pembelajaran Interaktif Bangun Ruang Matematika Surakarta. Jurnal Speed Sentra Penelitian Engineering dan Edukasi. Vol 6 No 22014. Hal 14-24.

[5] Teguh Wahyono, 2006, 36 Jam Belajar Komputer Animasi dengan Adobe Flash CS 3.Jakarta : PT Elex Media Komputindo

[6] Suyanto, M. 2003. Multimedia alat untuk meningkatkan keunggulan bersaing, Jakarta : Andi

[7] Rachmawati. Y. 2008. Bahan ajar diklat pendidik anakusia dini; Matematika untuk anak usia dini.Jakarta: Direktorat Pendidikan Anak Usia Dini. 